\title{
Euglossa paisa, a new species of orchid bee from the Colombian Andes (Hymenoptera: Apidae)
}

\author{
SANTIAGO RAMÍREZ
}

Museum of Comparative Zoology and Department of Organismic and Evolutionary Biology, Harvard University, 26 Oxford st., Cambridge, MA 02138, USA

Email:sramirez@oeb.harvard.edu

\begin{abstract}
A distinct new species of orchid bee, Euglossa paisa Ramírez n. sp., is here described. Various morphological characters suggest that this new taxon belongs to the subgenus Glossurella, a group composed of 21 species whose members occur throughout low and mid elevation tropical America. E. paisa n. sp. is morphologically closest to E. oleolucens Dressler, a species endemic to the montane region of southern Costa Rica, and these two to E. fuscifrons Dressler, a species endemic to the lowland wet forests of the northwest Amazon Basin. E. paisa is endemic to the Cordillera Central of Colombia, a region of elevated diversity and profuse endemism.
\end{abstract}

Key words: Apidae, Euglossini, Glossurela, bursigera species group, northern Andes, Cordillera Central, endemism, Colombia, orchid bee

\section{Introduction}

The brightly colored, long-tongued orchid bees (apid tribe Euglossini) inhabit the New World tropics and constitute a relatively well-studied group of animals (Roubik \& Hanson 2004). They have received significant attention in the past 150 years, in particular because they are the exclusive pollinators of nearly 700 orchid species. Although by the early 1960s only 90 species of orchid bees had been described (Moure 1967), the discovery of chemical baits that readily attract males to traps allowed much better sampling and promoted a rapid recent advancement in the taxonomy of the group, resulting in 190 currently recognized extant species (Ramírez et al. 2002; Moure \& Schlindewin 2002; Oliveira \& Nemésio 2003; Roubik 2004). While the discovery of new taxa appears to have reached a plateau in the well-surveyed countries of Meso-America (Roubik \& Hanson 2004), many species continue to be described from poorly studied and/or highly diverse countries like Brazil, Colombia, Ecuador and Peru. 
The tribe Euglossini contains five genera: Aglae, Eufriesea, Euglossa, Exaerete and Eulaema. Of these, Euglossa is the most speciose, with 108 described species. These are small to medium sized bees with iridescent metallic coloration that ranges from bronze to dark violet. Dressler $(1978,1982)$ and Moure (1989) divided the genus into six subgenera, although these were not accepted by Michener (2000). Glossurella, the second most speciose subgenus, currently contains 21 recognized species (Ramírez et al. 2002), the majority of which were described by Moure $(1968,1970)$ and Dressler $(1978,1982)$.

Males belonging to the subgenus Glossurella are easily recognized by their long tongues, slender bodies, separate semicircular depressions in the second sternum of most species (see Fig. 5), acute hind tibia, and complete (unnotched) anterior mid-tibial tufts.

Glossurella is known to occur throughout Meso- and South America. While approximately half of the species are widely distributed throughout the Amazon Basin, the other half appear to have more restricted ranges, both in the Amazon and elsewhere (Dressler 1982; Ramirez et al. 2002).

Here, a distinct new species of Euglossa (subgenus Glossurella) is described from the Central Andean Cordillera of Colombia.

\section{Materials and Methods}

A total of 27 male specimens from two locales $300 \mathrm{~km}$ apart were examined (Fig. 1). Specimens were collected as part of an ongoing project on the molecular phylogeny of the tribe Euglossini, in which orchid bee faunas are being sampled systematically on a yearround basis at various localities throughout Colombia by luring males with 10 different chemical baits in each trap. Upon capture, specimens were either transferred to a cyanide oxide killing-jar and then pin-dried, or preserved in 100\% ethanol. Integument coloration was described by eye under a Leica MZ75 microscope lit with an optic fiber High Intensity Illuminator (Fiber-Lite, series 180, Dolan-Jenner Industries, Inc.) adjusted to $80 \%$ power.

Anatomical terminology follows Michener (2000). Mesosoma width was measured at the anterior margins of tegulae. Drawings and body measurements were made using a camera lucida mounted on a Leica MZ75 dissecting microscope. Photographs were taken with a JVC digital camera (Ref. KYF75U) mounted on a MZ16 Leica microscope and further processed with Auto-Montage software (Syncroscopy 2002). Measurements were made from all available individuals $(N=27)$ unless otherwise indicated and are expressed as means with ranges in parentheses. Coefficients of variation were also calculated and reported.

Distribution maps were generated using the software package ArcGIS version 9.1 (ESRI 2004). 


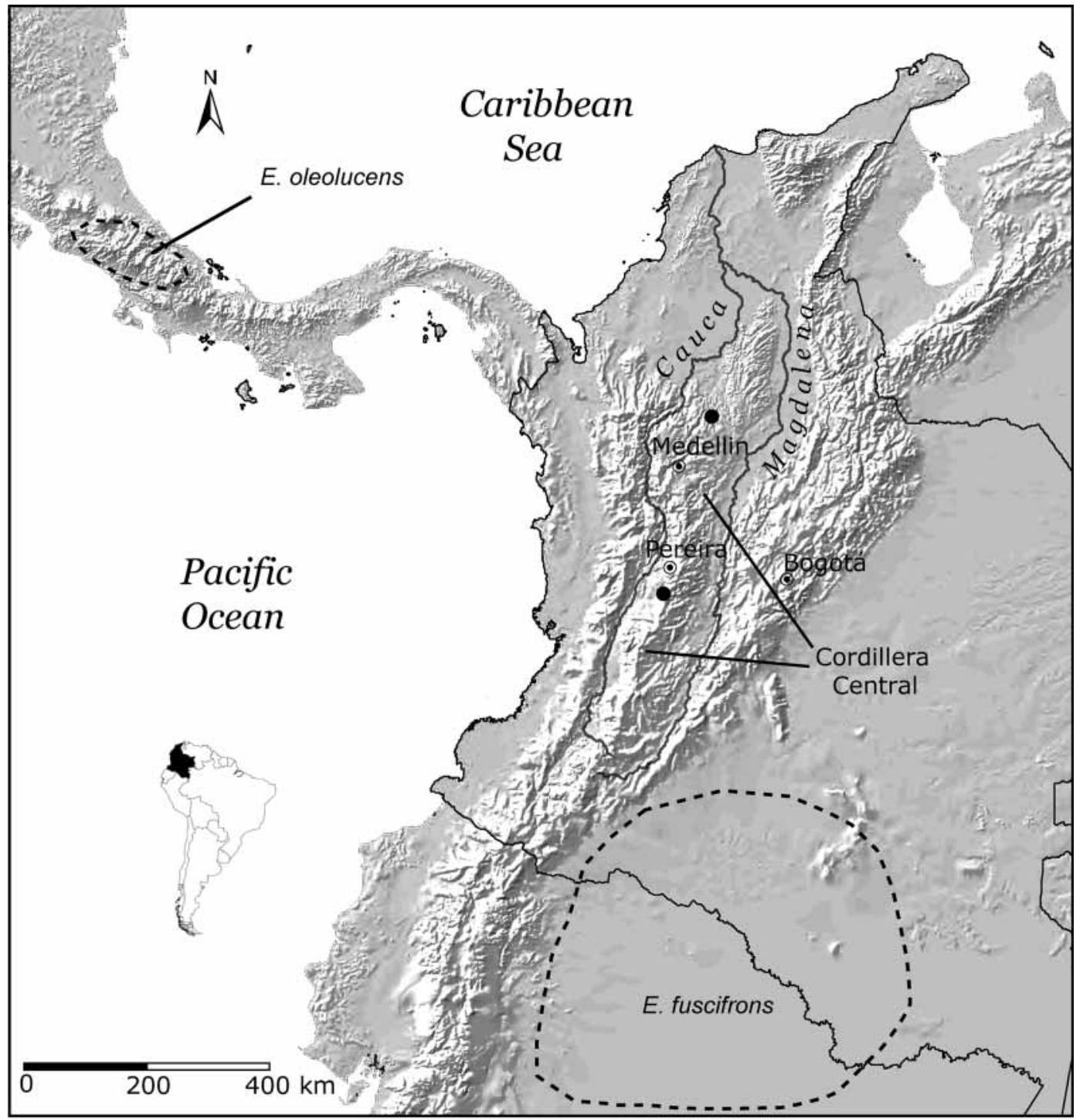

FIGURE 1. Map of the Colombian Andean region showing major cities, rivers and shaded relief of the three Andean ranges (Cordillera Oriental, Occidental and Central). The two collection localities for Euglossa paisa n. sp. are indicated with filled black circles. The northern location (Anorí) is the type locality.

\section{Species description}

Euglossa (Glossurella) paisa sp. nov.

(Figs. 1-8)

Male (females unknown) 
Dimensions. Total body length $11.75 \mathrm{~mm}(10.50-12.50 \mathrm{~mm})$; tongue in repose reaching terminal segment of metasoma; head width $4.50 \mathrm{~mm}(4.33-4.69 \mathrm{~mm})$; mesoscutal width $3.45 \mathrm{~mm}(3.02-4.00 \mathrm{~mm})$; metasoma width $4.71 \mathrm{~mm}(3.97-5.04 \mathrm{~mm})$.

Diagnosis. Males of Euglossa paisa are easily separated from those of all other members of subgenus Glossurella, except E. oleolucens Dressler and E. viridifrons Dressler, by lack of white paraocular markings on face; separated from males of $E$. oleolucens and males of $E$. viridifrons by presence of three distinct hair patches at basal end of midtibia, obvious blue-green integument (E. oleolucens males with two patches of hair in midtibia, bronzy green integument coloration; E. viridifrons males with one patch of hair in midtibia, dark green integument coloration). Males of $E$. fuscifrons Dressler are of similar coloration, but have tiny basal midtibial tufts and well developed white paraocular markings on face.

Head. Clypeus blue, protuberant in profile (Fig. 2); sutures, medial and lateral keels black (Fig. 4); paraocular area green; clypeoantennal area and frons blue-green with violet highlights; white paraocular markings absent; scape dark maroon without white markings, except in 3 out of 27 specimens showing faint markings < 1/4 scape length from apex. Mandible bidentate. Tongue length $10.64 \mathrm{~mm}(10.00-11.45 \mathrm{~mm}, n=8)$, reaching terminal metasomal sternum when in repose. Head length $2.53 \mathrm{~mm}(2.32-3.07 \mathrm{~mm})$; head width $4.50 \mathrm{~mm}(4.33-4.69 \mathrm{~mm})$. Upper interantennal distance $1.06 \mathrm{~mm}(0.95-1.19 \mathrm{~mm})$; clypeus length $1.30 \mathrm{~mm}(1.15-1.47 \mathrm{~mm})$; minimum clypeocular distance $1.98 \mathrm{~mm}$ (1.90$2.07 \mathrm{~mm})$.

Mesosoma. Scutum blue-green with violet highlights; scutellum blue-green with golden highlights in a few places; pronotum green with some violet highlights; mesepisternum shiny dark violet anteriorly (difficult to see, unless head is removed), sides green, light green with golden highlights near posterior margin; metepisternum light green on anterior half, brown on posterior half (latter difficult to see, unless metasoma is removed).

Metasoma. First four abdominal terga green as viewed from above, dark green with violet highlights as viewed from anterior, light green when viewed from posterior; terga VVII light green with substantial golden highlights; sterna green with golden highlights. Second sternite with two shallow semicircular depressions filled with sparse yellow setae (Fig. 5) separated by $1.45 \mathrm{~mm}(1.30-1.56 \mathrm{~mm}, n=7)$. Total body length $11.75 \mathrm{~mm}$ (10.50-12.50 mm); mesoscutum width $3.45 \mathrm{~mm}(3.02-4.00 \mathrm{~mm})$; metasoma width 4.71 $\mathrm{mm}(3.97-5.04 \mathrm{~mm})$.

Legs: Midtibia curved, slender with curved velvet area reaching apical end by anterior margin (Figs. 7,8); curved apical spur present. Three separate hair tufts basally on midtibia. Basal tuft (I) small, subcircular; middle tuft (II) arched, elongate; apical tuft (III) wider than (II), subtriangular (Fig 8). Hindtibia triangular, obtuse anteriorly, acute posteriorly, slightly arched apically (Fig. 6). 

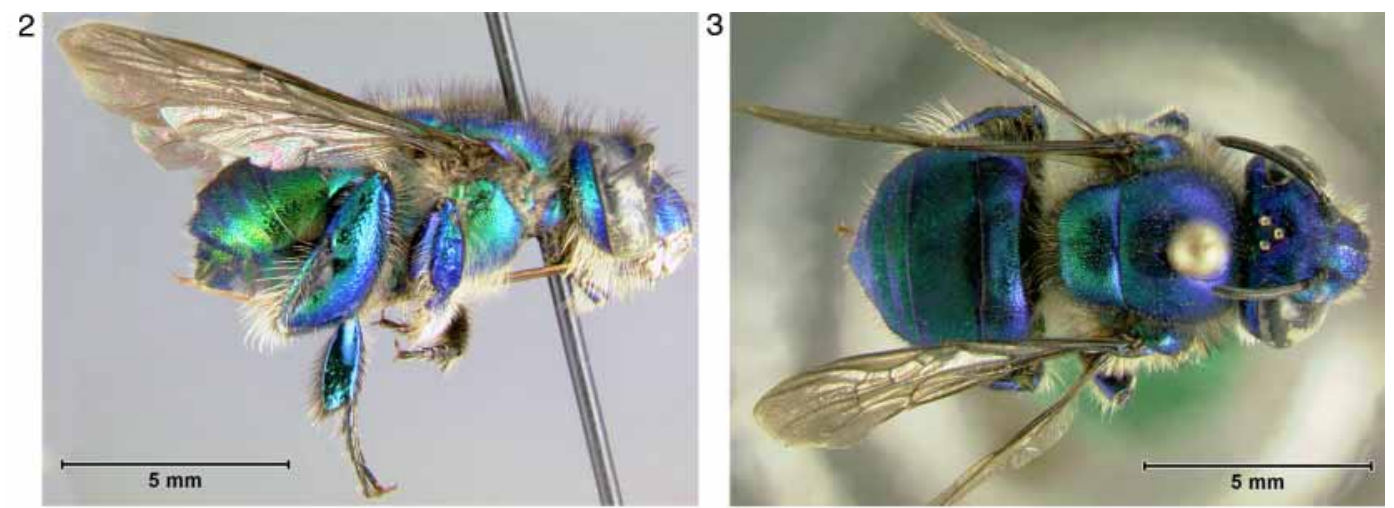

4
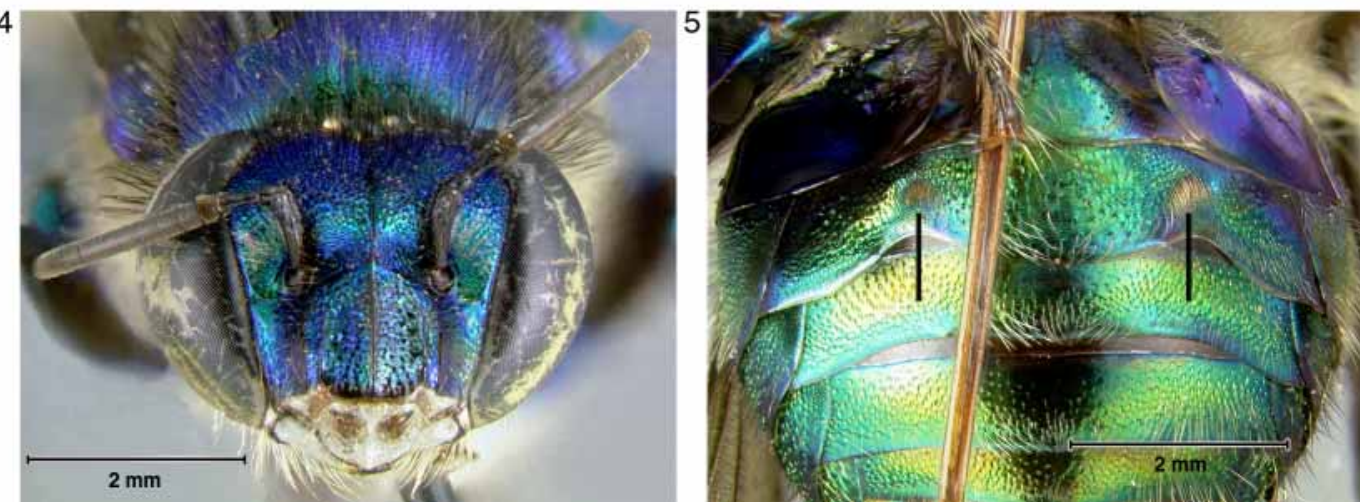

FIGURES 2-5. Euglossa paisa n. sp.: lateral profile (2) of male holotype (TA125); upper view (3) of male paratype (TA105); frontal view (4) of head of male holotype (TA125); ventral view (5) of metasoma of male paratype (TA124) showing semicircular depressions on second sternum.

Pilosity. Long ( $\sim 0.6 \mathrm{~mm})$ unbranched black setae on mesoscutum and scutellum (Fig. $2)$, dense in profile; dense long $(\sim 1.0 \mathrm{~mm})$, plumose light yellow hair on gena, pronotum, mesepisternum, episternum; unbranched sparse short $(\sim 0.2 \mathrm{~mm})$ black hair on metasomal terga; unbranched medium length $(\sim 0.4 \mathrm{~mm})$ sparse yellow setae on sterna. Foretibia, fore- and midbasitarsi fringed with both branched and unbranched long, yellow hair.

Wings. Wing venation maroon, somewhat translucent; wing membrane amber. Jugal comb at base of hind wing with $14-17$ bristles $(n=9)$, sometimes even variable within individuals.

Etymology. The specific epithet is from the vernacular Spanish word paisa, which alludes to the people and culture native to the "Paisa region", the area where Euglossa paisa is known to occur, i.e. the Colombian departamentos of Antioquia, Caldas, Quindio and Risaralda.

Holotype. COLOMBIA, Antioquia, Municipality of Anorí, La Forzosa Natural

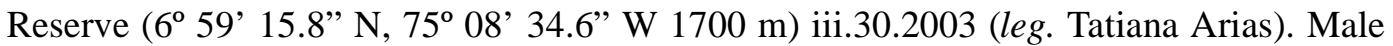
collected with trap baited with methyl salicylate, individually labeled as TA125, deposited in the Collection Alexander von Humboldt (Colombia). 

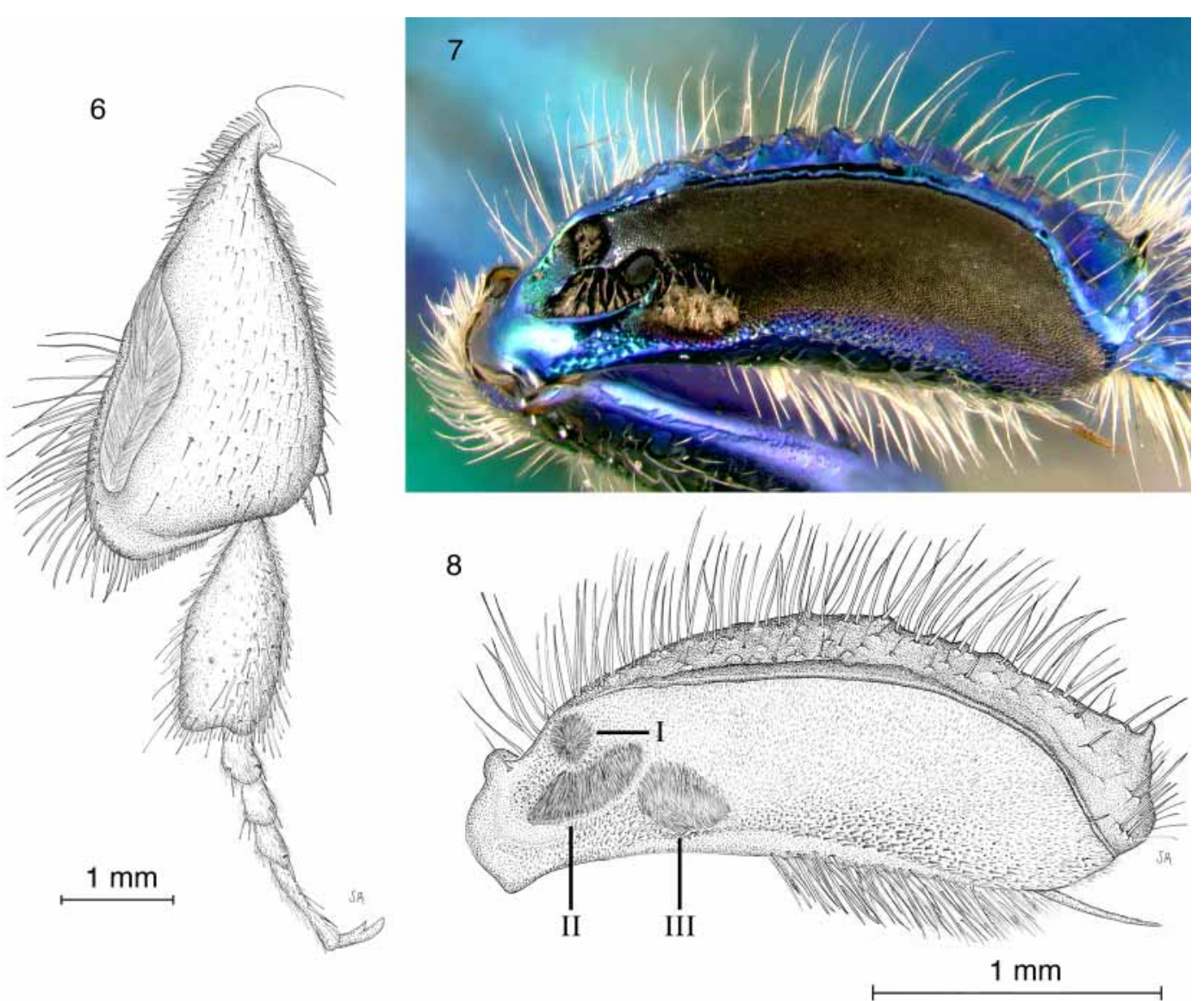

FIGURE 6-8. Euglossa paisa n. sp.: hind leg (6) of paratype (TA109) showing enlarged tibia with slit opening through which males deposit collected fragrances; midtibia (7) of the paratype (TA101); the midtibia line drawing (8) was based on a paratype specimen (TA124).

Paratypes. COLOMBIA. Antioquia, municipality of Anorí, La Forzosa Natural Reserve (6 59'15.8” N, 7508' 34.6” W 1700 m) iii.30.2003 (leg. T. Arias): 25 males collected in traps baited with methyl salicylate and cineole and individually labeled: TA084, TA085, TA090, TA098, TA101, TA105-TA116, TA118-TA124. Quindio,

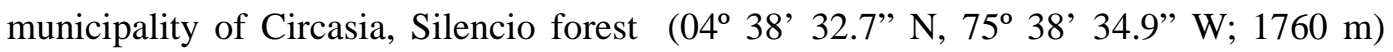
xi.14.2004 (leg. Jorge Hernán Bermudez): one male collected in trap baited with methyl salicylate, labeled BER55; i.27.05 (leg. J. H. Bermudez) one male collected in trap baited with methyl salicylate, labeled BER56. Paratypes will be distributed to the Museum of Comparative Zoology (MCZ, Harvard University), Collection Alexander von Humboldt (Colombia), Instituto de Ciencias Naturales (Universidad Nacional de Colombia), and National Museum of Natural History, Washington D.C. 
Variation. The 27 examined specimens showed considerable uniformity in most of the characters used in the description. For example, head length varied $6.11 \%$ and head width $2.15 \%$; interantennal distance varied $5.31 \%$, clypeus length varied $4.98 \%$, and clypeocular distance varied $2.00 \%$. Further, total body length varied $5.50 \%$, scutum width $6.48 \%$, and metasoma width $5.35 \%$. Tongue length varied $4.85 \%$. However, considerable variability was observed in the distance between the semicircular depressions of the second metasomal sternum (9.37\%). Also, the integument of the metasomal terga is dark green with violet highlights in specimens from the northern locality of Anorí and lighter green with golden highlights in specimens from the southern locality of Silencio (see Fig. 1). Although this could be due to preservation techniques rather than real variation since all Silencio specimens were deposited in $100 \%$ ethanol and all Anorí specimens were pindried.

\section{Discussion}

Based on the subgenera proposed by Dressler (1982), Euglossa paisa n. sp. is easily assigned to the subgenus Glossurella by the presence of two separated semicircular depressions on the second sternum, tongue at least as long as body, clypeus protuberant in profile, and male hind tibia with acute hind posterior margin.

Within the subgenus, this new species closely resembles the endemic Costa Rican species Euglossa oleolucens, in size and general morphology, but differs in the number of tufts on the midtibia (three in E. paisa and two in E. oleolucens) and the integumental color (green-blue in E. paisa and bronzy green in E. oleolucens). E. paisa also resembles, to a lesser degree, the Amazonian species Euglossa fuscifrons Dressler. They share almost identical coloration and general body morphology, but male E. paisa differ substantially from male E. fuscifrons as the former lacks paraocular markings, possesses semicircular depressions on the second sternum and has three hair tufts on the midtibia (E. fuscifrons males have two, the basal of which is tiny). In summary, E. paisa most closely resembles E. oleolucens and the most similar species to these two is E. fuscifrons.

Based on other orchid bee surveys made in the Colombian Andes (Bonilla-Gómez \& Nates-Parra 1992, Nates-Parras bee collection at Univerisdad Nacional de Colombia), it would appear that E. paisa is absent from the western and eastern Cordilleras and may be endemic to middle elevations of the Cordillera Central of Colombia. This species has only been recorded between 1700 and 1760 m elevation. Although additional specimens might demonstrate that it occurs in a slightly wider altitudinal range, it is unlikely that its range will increase much at the upper boundary since both diversity and abundance of orchid bees in general drop drastically above $1700 \mathrm{~m}$ (Nates \& González 2000). Moreover, records of orchid bees above $2000 \mathrm{~m}$ elevation are rare (Ramirez et al. 2002). With respect to the lower boundary of the range, J. H. Bermudez and the author are carrying out an extensive year-round ongoing survey of the orchid bee communities at various 
elevations (900, 1100, and $1600 \mathrm{~m}$ ) in the Cordillera Central of Colombia, and to date (eight months into the project), E. paisa has not been collected. These observations, in addition to the well-documented dramatic altitudinal stratification of the Andean forests (Escobar et al. 2005 and references therein) and the previously documented altitudinal stratification of orchid bee faunas elsewhere in tropical America (Roubik \& Hanson 2004), suggest that E. paisa occupies an extremely narrow $(\sim 100 \mathrm{~m})$ corridor at the upper boundary of the altitudinal range of orchid bees.

While the limited geographical data presented here suggest that the range of E. paisa might be restricted to the northern portion of the Andean Cordillera Central (Fig. 1), no information is currently available on the composition of the orchid bee fauna in the southern part of the range. Recent studies have shown that several endemic species of birds and frogs are only found in the northern part of the Cordillera Central (Lynch 1999; Cuervo et al. 2005), whereas other studies have shown that additional species of frogs are endemic to the whole range (Lynch 1986). Although limited distributional data are available for E. paisa, it seems unlikely that its range extends further south into Ecuador and Peru, as that region has been sampled by Williams, Whitten and Dressler (University of Florida Herbarium, FLAS), and E. paisa has not been collected.

The two putative closest relatives of E. paisa are allopatric with regard to it as well as to each other. Euglossa oleolucens, possibly the closest relative of E. paisa, is endemic to mid-elevation seasonally wet forests of southern Costa Rica (Fig. 1) (Roubik \& Hanson 2004), a region 9 degrees north of the equator. Thus, it is possible that the altitudinal range where E. oleolucens occurs (1000-1300 m) provides a similar climate regime to that of $E$. paisa $(\sim 1700 \mathrm{~m})$ farther south, 4-6 degrees north of the Equator. In contrast, E. fuscifrons, possibly the closest relative of the putative paisa-oleolucens lineage, occurs only in low elevation $(250 \mathrm{~m})$ rain forests of the northwest Amazon Basin (Fig. 1) (Ramírez et al. 2002). Robust and thoroughly sampled phylogenetic analyses may help understand the role (if any) of the orogeny of the Andes in the speciation events that gave rise to E. paisa and its close relatives.

\section{Acknowledgments}

I thank Tatiana Arias and Jorge Hernán Bermudez-both themselves paisas-for collecting the material from Antioquia and Quindio, respectively. Comments by Bruce Archibald, Adam Bahrami, Manus Patten, Laurence Packer, Naomi Pierce, Beth Pringle, Tiago Quental and two anonymous reviewers helped improve the manuscript. Stefan Cover (MCZ, Harvard University) gave useful advice on various aspects of the species description; Bruce Archibald gave technical assistance with microscopy, and Gary Alpert allowed me to use his microscope and digital photography equipment for the AutoMontage work. This research was supported by grants from the Putnam Expedition Fund (Museum of Comparative Zoology), the Colombia Biodiversa Fund (Fundación Alejandro 
Angel Escobar), and the David Rockefeller Center for Latin American Studies (Harvard University). Specimens loaned by the Instituto Alexander von Humboldt (Bogotá,

Colombia) under the agreement No. 319 were exported under permit No. 1150, granted to

the author by the Dirección de Ecosistemas of the Ministerio de Ambiente, Vivienda y Desarrollo Territorial (Colombia).

\section{References}

Bonilla-Gómez, M.A. \& Nates-Parra, G. (1992) Abejas Euglosinas de Colombia (Hymenoptera: Apidae) I. Claves ilustradas. Caldasia, 17, 149-172.

Cuervo, A.M., Cadena, C.D., Krabbe, N. \& Renjifo, L.M. (2005) Scytalopus stilesi, a new species of tapaculo (Rhinocryptidae) from the Cordillera Central of Colombia. The Auk, 122, 445-463.

Dressler, R.L. (1978) An infrageneric classification of Euglossa, with notes on some features of special taxonomic importance (Hymenoptera; Apidae). Revista de Biología Tropical, 26, 187198.

Dressler, R.L. (1982) New species of Euglossa. III. The bursigera species group (Hymenoptera: Apidae). Revista Biología Tropical, 30, 131-140.

Escobar, F., Lobo, J.M. \& Halffter, G. (2005) Altitudinal variation of dung beetle (Scarabaeidae : Scarabaeinae) assemblages in the Colombian Andes. Global Ecology and Biogeography, 14, 327-337.

ESRI. 2004. ArcGIS. Version 9.1 [computer program]. Redlands, CA. ESRI Inc. (USA).

Lynch, J.D. (1986) Origins of the high Andean herpetological fauna. In: F, Vuilleumier, \& M. Monasterio (Ed.), High altitude tropical biogeography. Oxford University Press, Oxford UK, pp. 478-499.

Lynch, J.D. (1999) Ranas pequeñas, la geometría de evolución, y la especiación en los andes colombianos. Revista de la Academia Colombiana de Ciencias Exactas, Físicas y Naturales, $23,143-159$.

Michener, C.D. (2000) The bees of the world. Johns Hopkins University Press, Baltimore, MD, 913 + xiv pp.

Moure, J.S. (1967) A check-list of the known Euglossine bees (Hymenoptera, Apidae). Atas do Simpósio sôbre a Biota Amazônica, 5, 395-415.

Moure, J.S. (1968) Especies novas de Euglossa da América Central (Hymenoptera, Apidae). Boletim da Universidade do Paraná, 3, 1364.

Moure, J.S. (1970) The species of euglossine bees of Central America belonging to the subgenus Euglossella (Hymenoptera, Apidae). Anais da Academia Brasileira de Ciencias, 42, 47-157.

Moure, J.S. (1989) Glossuropoda, novo subgênero de Euglossa, e duas espécies novas da Amazônia, do mesmo subgênero (Apidae-Hymenoptera). Memórias do Instituto Oswaldo Cruz, 84, 387-389.

Moure, J.S. \& Schlindwein, C. (2002) A new species of Euglossa (Euglossella) Moure from the Northeastern Brazil (Hymenoptera, Apidae). Revista Brasileira de Zoología, 19, 585-588.

Nates, G. \& González, V.H. (2000) Notas sobre el nido de Eulaema polychroma (Hymenoptera: Apidae: Euglossini). Actualidades Biológicas, 22, 83-90.

Oliveira, M.L. \& Nemesio, A. (2003) Exaerete lepeletieri (Hymenoptera: Apidae: Apini: Euglossina): a new cleptoparasitic bee from Amazonia. Lundiana, 4, 117-120.

Ramírez, S., Dressler, R.L. \& Ospina, M. (2002) Orchid bees (Hymenoptera: Apidae: Euglossini) from the Neotropical Region: A species checklist with notes on their biology. Biota Colombiana, 3, 7-118. 
zootaxA Roubik, D.W. (2004) Sibling species of Glossura and Glossuropoda in the Amazon Region (Hymenoptera: Apidae: Euglosssini). Journal of the Kansas Entomological Society, 77, 235253.

Roubik, D.W. \& Hanson, P.E. (2004) Orchid Bees of Tropical America: Biology and Field Guide. INBIO, Heredia, Costa Rica, 370 pp.

Syncroscopy (2002) (a division of Synoptics Inc.). AUTO-MONTAGE. Version 4.0 [computer program]. Frederick, Maryland: SYNOPTICS Inc (USA). 